\title{
MARGINAIS, PROSTITUTAS E CAPETAS URBANOS: UM OLHAR PÓS-COLONIAL SOBRE A QUIMBANDA E OUTRAS IDENTIDADES AFRO-RELIGIOSAS
}

\author{
Outsiders, prostitutes and urban devils: A post-colonial view about the Quimbanda and \\ others afro-religious identities
}

\author{
Rodrigo Marques Leistner ${ }^{1}$
}

Recebido em 24/10/2015; aceito em 10/06/2016

\begin{abstract}
Resumo: O artigo versa sobre a relação entre as práticas afro-brasileiras menos ortodoxas, como a Quimbanda, e o discurso promovido como base do projeto de legitimação social das religiões de matriz africana na atualidade, baseado na ideia de reafricanização. Tomando como aporte teórico a crítica póscolonial, o texto relativiza a idéia de eficácia de um discurso voltado às matrizes africanas, observando o caráter desestabilizador de algumas práticas religiosas mais sincréticas, as quais têm sido desconsideradas pela academia e menosprezadas pelos atores africanistas que negociam políticas na esfera pública.
\end{abstract}

Palavras-chave: religiões afro-brasileiras; quimbanda; crítica pós-colonial.

\begin{abstract}
This article deal about the relation between unorthodox afro-brazilian practices, such as the Quimbanda, and the speech based in the social legitimating project of the contemporary African religions, based on the reafricanization idea. Taking theoretically for that reflection the post-colonial critic, the text relativize the idea of efficacy of a speech turned to Africans matrices, observing the unstabilizer character of some syncretics religious practices, which has been unconsidered by the academy and underestimated by africans actors who negotiate policies in the public sphere.
\end{abstract}

Words key: afro-brazilian religions; quimbanda; post-colonial critic.

\section{Notas sobre uma paisagem etnográfica ambígua}

"Bem-vindo à casa de Maria Padilha, seu moço". Essa era a frase de recepção que eu recebera ao chegar à curimba, espécie de sessão festiva destinada àquelas divindades cultuadas na Quimbanda, Exus e Pombagiras, em uma de minhas primeiras incursões etnográficas nos terreiros afro-brasileiros $\underline{2}$. O enunciado receptivo era entoado por uma voz estridente, com tom de embriaguez, vinda de um mulato alto, de cabelos compridos e longas unhas vermelhas, envolvido num vestido negro de um cetim qualquer. Era o médium que incorporava a líder espiritual das atividades quimbandeiras

\footnotetext{
${ }^{1}$ Doutor em Ciências Sociais pela Universidade do Vale do Rio dos Sinos (UNISINOS), Rio Grande do Sul. Atualmente desenvolve estudos de pós-doutoramento na mesma instituição. É pesquisador do Laboratório de Políticas Culturais e Ambientais do Brasil - LAPCAB. E-mail: rodrigoless@yahoo.com.br.
}

2 O contexto empírico que municia esta reflexão parte de uma combinação entre incursões etnográficas realizadas no universo dos terreiros de matriz africana do Rio Grande do Sul e a análise de dados secundários disponíveis na literatura antropológica especializada. 
naquele templo: Maria Padilha das almas, minha anfitriã. Impossível não recordar a comparação feita na etnografia de Norton Corrêa (1998, p.53), donde tanto as vestimentas quanto o clima do evento religioso relembram os quadros que outrora retrataram os cabarés parisienses da belle époque francesa, na obra de ToulouseLautrec. No terreiro que eu visitava, homens, mulheres e travestis (muitos deles) incorporavam divindades que bebiam, fumavam, mantinham gestos de teor lascivo, num clima que aliava conotações eróticas a uma simbólica permeada por nuances de violência e desordem ritual. Deve-se considerar que na representação mítica daquelas entidades, observa-se um imaginário sobre seres espirituais com um suposto passado humano marginal, plasmados junto a aspectos demoníacos - estes advindos do entrecruzamento das culturas africanas e ocidentais. Afinal de contas, Pombagira Maria Padilha, quando viva, fora mulher de sete homens, dona de um cabaré, possui cornos e patas de cavalo como membros inferiores. Zé Pelintra, Exu muito respeitado, fora um típico malandro urbano, marginal dos recantos mais obscuros dos subúrbios.

Junto a todos aqueles médiuns e suas divindades diabólicas, o terreiro estava repleto de indivíduos das mais variadas origens sociais, os quais interagiam com as divindades incorporadas e negociavam a resolução de seus problemas cotidianos. A experiência religiosa transformava-se numa espécie de mercado de soluções mágicas, e ali se encontrava um etnógrafo perplexo diante daquela rica e confusa paisagem recheada de magia, indisciplina e erotismo -, a qual desestabilizava a idéia de centro, de ordem e da fria racionalidade que permeia a lógica hegemônica da modernidade.

A perplexidade referida ainda se relacionava com algumas contradições existentes entre práticas como a Quimbanda - aqui tomadas como experiências religiosas cotidianas e centrais na realidade dos templos afro-brasileiros - e as iniciativas políticas de legitimação social atualmente empreendidas pelos atores do campo afroreligioso na esfera pública do país. Destaque-se que os códigos simbólicos presentes em cultos como os de Exus e Pombagiras configuram justamente aqueles elementos rituais e cosmológicos que tendem a ser negados nos discursos e projetos de legitimação acionados pelos agentes políticos ligados às religiosidades afro-brasileiras ${ }^{3}$. Na

\footnotetext{
3 Tal perspectiva relaciona-se não apenas com a presença de signos aparentemente "estranhos" ao universo religioso convencional (a desordem dionisíaca dos cultos quimbandeiros), mas ainda com as características míticas associadas às divindades da Quimbanda. Como se sabe, no amplo processo de ressignificação dos panteões africanos durante a diáspora, divindades como Exu foram associadas ao demônio da cristandade, em representações que incidiram diretamente na repressão aos cultos de matriz africana (Cf. ORTIZ, 1978; PRANDI, 2001). Essa dinâmica pode ser percebida atualmente com base nos
} 
atualidade, esses projetos têm sido ativados a partir da lógica de "reafricanização", movimento que combina processos ativos de desincretização simbólica aliados a um discurso voltado às matrizes afro (LÉPINE, 2005; SILVA, 1995). Tais discursos, orientados a um enquadramento em relação às práticas e sistemas de representação mais aceitos socialmente, tendem a rechaçar não apenas o sincretismo e as perspectivas "mágicas" (assim se aproximando do conceito de "religião" tradicional), mas também aquelas concepções do sagrado distantes de um modelo representacional típico das religiosidades ocidentais - nas quais violência e erotismo constituem elementos "estranhos" (Cf. CARVALHO, 1990). Entretanto, se o processo de reafricanização se apresenta como evidente no âmbito dos agenciamentos políticos presentes na esfera pública, o que se observa de modo mais consistente no cotidiano dos terreiros se refere à expansão de modalidades rituais permeadas pelos signos da desordem e das concepções mágicas, cujo desenvolvimento se efetua a partir de bricolagens evidentes ${ }^{4}$. A expansão de denominações como a Quimbanda em tal universo é sintomática a esse respeito.

Parece correto avaliar que nos encontramos diante de um deslocamento de perspectivas através das quais os atores do campo afro articulam suas pertenças e constroem seus sistemas de representação em acordo com os diferentes espaços pelos quais circulam. Enquanto no âmbito de uma religiosidade semiprivada (praticada no interior dos templos) verifica-se a expansão de rituais mágicos e dotados dos signos típicos da carnavalização ritual (BAKHTIN, 1987), na esfera pública (espaço em que se negociam demandas de legitimação) observa-se a configuração de identidades religiosas contíguas às representações mais alinhadas com a tradição ocidental. Desse modo, no contexto das movimentações contemporâneas que se referem ao universo afrobrasileiro, de um lado percebe-se a ampliação de práticas como a Quimbanda (mágicas, pouco ortodoxas e ancoradas num modelo de representação do sagrado muito singular); de outro lado, evidencia-se a constituição de identidades e discursos que reivindicam uma suposta pureza cultural africana através de procedimentos de racionalização ritual e

ataques efetuados pelos segmentos pentecostais em relação ao campo afro-religioso, os quais são fomentados, em grande medida, por exegeses sobre Exus e Pombagiras (Cf. SILVA, 2013).

4 Utilizo a expressão "bricolagem evidente" em contraposição aos discursos políticos e teológicos baseados na ideia de pureza religiosa, os quais configuram a base dos atuais projetos de legitimação do campo religioso afro-brasileiro (Cf. LEISTNER, 2012). Desse modo, se está recusando qualquer perspectiva que desconsidere a característica híbrida inerente a qualquer forma cultural ou religiosa (SHAW e STEWART, 1994). 
cosmológica, desvelando-se um quadro em que a reafricanização reaproxima as religiosidades afro-brasileiras das grandes religiões universais (PRANDI, 1991) .

Ocorre que essa aparente disjunção entre o que se processa no cotidiano dos templos e o que se evidencia em termos de agenciamentos na esfera pública não se desenvolve sem consequências políticas para os atores envolvidos, engendrando-se um quadro no qual certas relações de poder podem ser projetadas sobre o campo afro de acordo com hierarquias de valor mediadas pela racionalização dos códigos religiosos. Enquanto determinados agentes se estabilizam como detentores do saber ritual autêntico, assim ocupando posições legitimadas no campo religioso (especialmente aqueles envolvidos com os ideais de reafricanização), outros são realocados nos registros mais subalternos desse mesmo campo, sobretudo aqueles que se identificam ou passam a ser identificados junto aos códigos de práticas outsiders, como a Quimbanda ${ }^{6}$.

É justamente sobre os aspectos políticos dessa disjunção que esse trabalho se desenvolve. Por um lado, trata-se de avaliar as complexidades que envolvem o processo de reafricanização nas religiosidades afro-brasileiras, do ponto de vista dos condicionamentos identitários gerados por tal movimento: seriam esses discursos efetivos em seus propósitos de legitimação social? Haveria novas assimetrias e condicionamentos decorrentes dessas estratégias, assim gerando-se relações de poder endógenas ao próprio campo dos terreiros? Por outra via, trata-se de refletir sobre os prováveis significados políticos contidos naquelas práticas que se encontram na contramão desse processo: formas rituais como a Quimbanda representariam apenas um obstáculo aos projetos de legitimação social do campo afro? Ou, ao contrário, poderiam ser percebidas em termos contraculturais, assim comportando significados políticos e contestatórios - mesmo que na contramão daqueles discursos de legitimação?

Destaque-se que essas possibilidades de análise têm sido pouco referidas pelos estudos especializados, constatando-se um grande volume de abordagens que se restringem a averiguar os significados da reafricanização nas religiões afro-brasileiras.

\footnotetext{
${ }^{5}$ Por mais paradoxal que pareça, ao estar conjugada por processos de racionalização ritual e cosmológica (em oposição à bricolagem) a reafricanização reaproxima os sistemas de representação básicos das religiões afro-brasileiras das matrizes simbólicas características das grandes religiões universais. Nesse sentido, o pressuposto "retorno ao continente africano" reside mais em processos de negociação identitária do que em concepções metafísicas e cosmológicas próprias a um sistema religioso original (Cf. LEISTNER, 2014).

${ }^{6}$ Utilizo a expressão outsider no sentido de Howard Becker (2008), com respeito aos processos sociais de rotulação que conferem o estatuto do desvio a determinados grupos e suas práticas.
} 
Mais do que isso, tais estudos chegam a conceituar a reafricanização como movimento inequívoco e monolítico no desenvolvimento dessas religiosidades, desconsiderando a emergência e expansão de formas rituais como a Quimbanda ${ }^{7}$. Decerto, realidades como essas desvelam um interessante campo para interpretações renovadas sobre as religiões de matriz africana na sociedade brasileira, seja sobre os aspectos teológicos envolvidos (relacionados com o significado de novas formas rituais em expansão), seja sobre os aspectos simbólicos e políticos daquele movimento contraditório aqui assinalado. É sobre essa última possibilidade que este trabalho se debruça, analisando-se a relação paradoxal entre as vivências religiosas cotidianas nos cultos afro-brasileiros (sobretudo aquelas observadas na Quimbanda) e as propostas de (re)construção político-teológicas empreendidas na busca pela legitimação social dessas práticas.

Finalmente, compreende-se que a problemática enunciada encontra no marco teórico pós-colonial uma base importante para a análise. Amparado numa perspectiva discursiva acerca da realidade social, tal enfoque favorece uma abordagem desconstrutiva dos fatos analisados, nos seguintes sentidos: (i) a concepção descentrada de sujeito, contemplada nesses estudos, possibilita uma observação das lógicas de construção identitária em jogo no campo afro-religioso contemporâneo, avaliando-se tanto as relações de poder inerentes ao processo de reafricanização quanto as possíveis perdas (ou ganhos) implicadas em reconstruções identitárias cristalizadas (caso dos discursos relativos à pureza cultural africana); (ii) a avaliação sobre os locais híbridos de enunciação, tópico recorrente na teoria pós-colonial, permite reconsiderar as possibilidades de um contra-discurso afro-religioso emergente nas próprias experiências religiosas outsiders, as quais podem ser aqui reinterpretadas como um texto, no sentido de Barthes (2003), e dessa maneira, como espaço de enunciação discursiva contestatória.

Dito de outro modo, com base no viés pós-colonial, esta análise propõe relativizar não apenas a ideia de que as políticas de reafricanização sejam tão efetivas em seus propósitos políticos (como proposto em boa parte dos estudos especializados), mas ainda a noção de que práticas como a Quimbanda sejam apenas expressões rituais

\footnotetext{
7 Frigerio (2005) chega a propor que o movimento de reafricanização constitui um "último estágio" no desenvolvimento das religiões afro-americanas. Por sua vez, apenas o trabalho de Capone (2004) faz menção à preponderância que os cultos de Exus e Pombagiras adquiriram no cotidiano dos terreiros afrobrasileiros, ainda que ritualizados em arranjos religiosos mistos - em conjunto com a Umbanda e o Candomblé. Em casos como no Rio Grande do Sul (Cf. ORO, 2012), vertentes como a Quimbanda chegaram a adquirir o status de denominação mais concorrida no mercado dos bens afro-religiosos.
} 
que fomentam visões distorcidas sobre as religiosidades de matriz africana em geral (como proposto pelos atores africanistas que negociam políticas na esfera pública). Ao contrário, sustenta-se que práticas religiosas como a Quimbanda podem ser mais bem compreendidas quando concebidas como uma linguagem de contestação ${ }^{8}$.

\section{A Quimbanda na cultura religiosa afro-brasileira}

É sabido que no Brasil as religiosidades de matriz africana se desenvolveram a partir das tradições dos Iorubás, Jejes e Bantos ${ }^{9}$. O que é devido ressaltar é que se observa uma predominância na adoção do panteão iorubano na configuração dos ritos que se organizaram nos espaços que Frigerio (2005) caracterizou como de diásporas primárias, ou seja, os locais de origem dos rituais mais africanizados, como Salvador, Porto Alegre, Recife e São Luiz. Fora nessas localidades que, no período pósescravatura, surgiram os primeiros terreiros afro-brasileiros, como os do Candomblé baiano, do Batuque gaúcho, do Xangô pernambucano e da Casa de Minas maranhense ${ }^{10}$. Em geral, tais vertentes mantêm em comum a adoção do culto aos orixás dos Iorubás e podem ser compreendidas como portadoras de estruturas litúrgicas mais rígidas quando comparadas com as religiosidades de origem Bantu, que se disseminaram no sudeste do país e que influenciaram o aparecimento das vertentes mais sincréticas.

A noção de ancestralização, inerente à cultura religiosa de origem africana em geral, se demonstra imprescindível para a compreensão dessas diferenças entre a manutenção de liturgias concisas na cultura iorubana e sua dissolução nos cultos de origem Bantu. Conforme Laleye (2002), a ancestralização refere-se ao processo de evolução espiritual do ser de passado humano vivido, que ao morrer, passa a ser cultuado em diferentes possibilidades. Num primeiro momento, o ancestral direto, pertencente ao núcleo familiar, é venerado como divindade de uma comunidade restrita. No entanto, aqueles seres que realizaram feitos maiores, propícios para serem relembrados nas narrativas míticas por comunidades mais amplas, passam a ser reverenciados por diversas coletividades. Essa diferenciação caracteriza dois conjuntos de entidades que Laleye (2002) classifica como maiores e menores. Nessa perspectiva, os orixás iorubanos podem ser compreendidos como divindades de ampla devoção, os

\footnotetext{
${ }^{8}$ No sentido de Georges Balandier (1976).

${ }^{9}$ Neste sentido, ver os trabalhos de Carneiro (1957; 2008) e Lody (1987).

${ }^{10}$ Essas particularidades locais foram sistematicamente observadas no amplo trabalho de Bastide (1960).
} 
quais sobreviveram na memória coletiva das populações negras no Brasil, ao contrário dos inquices bantos, antepassados familiares potencialmente esquecidos em decorrência do processo de desestruturação da família negro-africana no processo de escravidão ${ }^{11}$. Nessa lógica, o culto aos antepassados bantos não apenas foi dificultado, como foram favorecidas duas situações: por um lado, a adoção do panteão Iorubá; por outro, a aproximação com a concepção de espírito do kardecismo, que começava a ser introduzido no Brasil em fins do Século XIX ${ }^{12}$. Conforme inferiu Arthur Ramos (1979), a afinidade entre os cultos bantos e o espiritismo fundamenta-se justamente na possibilidade de culto aos antepassados próximos. Dessa maneira, de um lado se observa a formatação de cultos de raízes africanas mais ortodoxas, de origem Iorubá, caso dos Candomblés e Batuques; de outro lado, constata-se a proliferação de bricolagens entre raízes africanas diversas (bantos, iorubás) e as tendências espíritas, católicas e indígenas.

Ressalte-se que esse movimento de sincretismo se amplia consideravelmente no sudeste brasileiro, região de ampla concentração de grupos negros de origem Bantu. No Rio de Janeiro, que contava com cultos semelhantes ao Candomblé, surge uma nova adaptação cultural por volta de 1850, que se processa através da utilização do português como a língua dos cultos, da possessão por espíritos desencarnados e não apenas por orixás, seguindo o exemplo das mitologias Bantu: a Macumba carioca. Outra adaptação surge ainda no Rio de Janeiro, por volta dos anos 1920, caso da Umbanda, descrita por Ortiz (1978) a partir dos conceitos de "empretecimento" e "embranquecimento", que designam o surgimento da vertente em duas vias: o empretecimento do kardecismo espírita e o embranquecimento da Macumba.

Conforme demonstrou Camargo (1961), nas práticas sincréticas como Umbanda e Macumba, a influência do espiritismo e da angeologia católica favoreceu a reinterpretação dos orixás iorubanos como espíritos divididos em falanges, agregandose a eles o culto de antepassados, como os antigos negros escravos (preto-velho) e indígenas (caboclo). Nessas ressignificações, o orixá Exu dos iorubás, bem como a divindade Bonbojira, dos bantos, passaram a configurar os espíritos de antepassados hierarquicamente inferiores de acordo com a perspectiva de evolução kardecista, surgindo então o Exu e seu par mítico, Pombagira, os quais foram identificados a

\footnotetext{
${ }^{11}$ Sobre a desestruturação das famílias africanas, ver Silva (1995) e Bastide (1960).

12 Consultar os trabalhos de Ortiz (1978) e Camargo (1961).
} 
malandros e prostitutas endiabrados. São essas duas categorias de entidades que constituirão a base do culto da Quimbanda: uma espécie de subcategoria ora da Macumba carioca, ora da Umbanda, que se disseminou por todo o país.

É justamente sobre esse caráter "endiabrado" de entidades como Exu e Pombagira que se detecta uma provável lógica colonial incidente sobre as representações sociais construídas sobre as religiosidades afro-brasileiras. Conforme recorda Ortiz (1978), o Exu dos iorubás corresponde a uma espécie de mensageiro, intermediário que transmite ordens, recompensas e punições. Assim, designa o ente que pode introduzir o acaso na ordem dos acontecimentos. Conforme esse autor, a característica trickster levou pesquisadores e leigos a analogias errôneas entre o "Hermes" iorubano e o demônio católico. No entanto, é com base no forte dualismo que perpassa a ideologia umbandista que Exu será definitivamente deslocado ao mundo das trevas. A partir da influência relativa à racionalização do mundo dos espíritos executada pelo kardecismo, o pensamento umbandista incorporou a hierarquia mística entre espíritos puros e imperfeitos, deslocando os segundos para uma subcategoria na qual pudessem evoluir. Assim surge a Quimbanda, uma divisão dicotômica entre bem e mal na qual Umbanda e Quimbanda constituem um par oposto e complementar.

Se é fato que no desenvolvimento contemporâneo das religiosidades de matriz africana se observam imbricações rituais nas quais Umbanda, Quimbanda e vertentes mais africanizadas (como Batuque, Xangô ou Candomblé) são praticadas alternadamente no mesmo templo (Cf. PRANDI, 1991; CORRÊA, 1994), também é necessário observar que essa sobreposição não se faz sem uma hierarquia sólida na qual o lado sincrético tende a ser compreendido como "espécie de lata de lixo simbólica da experiência religiosa afro-brasileira" (CARVALHO, 1990, p.13). Examinando a relação entre a Jurema e o Xangô pernambucano (práticas afro-brasileiras superpostas), Carvalho (1990) verificou a polaridade interna entre os rituais que apresentam ordem e coerência (o que os coloca em pretensões de legitimidade com outras religiões) e os ritos que de fato assumem os conteúdos rejeitados pelas demais denominações. Dessa maneira, não apenas os cultos que se ocidentalizaram (caso da Umbanda) discriminaram simbolicamente as religiosidades sincréticas, mas as próprias religiões africanas mais ortodoxas. Ainda conforme Carvalho (1990), o campo religioso brasileiro projeta uma cadeia regressiva de deslocamento simbólico que tem em seu pólo inferior aqueles cultos que aceitam o resíduo ritual rejeitado por outras denominações, incorporando os 
elementos de desordem e violência que parecem contradizer as noções convencionais acerca do fenômeno religioso:

[...] com idêntico mecanismo opera o kardecismo que, colocando-se ao lado do cristianismo, transfere o que não aceita para as religiões afro-brasileiras. A umbanda branca faz o mesmo: alia-se ao cristianismo e ao espiritismo, vendo-se pacífica, pura e ordenada, atribuindo ao candomblé e à macumba (e seus equivalentes) a violência e a desordem. Quanto ao xangô e ao candomblé, fazem o mesmo em relação à jurema e à macumba, que são finalmente os únicos cultos capazes de reconhecer toda a violência e a desordem do sagrado brasileiro (CARVALHO, 1990, p.10).

O que se demonstra pertinente é que, mesmo no campo afro-brasileiro, os elementos ligados à desordem, violência e erotismo (presentes nas práticas híbridas como a Quimbanda, Macumba e Jurema) são tidos como características a serem reprimidas e superadas pela atual tendência de reafricanização, a qual tornaria o campo africanista mais puro. Pode-se compreender que essa visão negativa sobre o caráter violento, erótico e desordeiro das práticas híbridas, bem como a valorização da pureza das tradições Iorubá configuram noções que estiveram sedimentadas nos próprios discursos dos intelectuais que abordaram a temática das religiões afro-brasileiras.

A tendência dicotômica entre pureza e sincretismo, expressa nas comparações entre Iorubás e Bantos, fora incorporada até mesmo pelo estudioso clássico dessas religiosidades: Roger Bastide. Em sua análise (Cf. BASTIDE, 1983), os cultos estruturados em cidades litorâneas do nordeste estariam mais próximos de uma sociedade pré-capitalista, de valores predominantemente tradicionais e comunitários, o que teria favorecido a reconstrução de uma África perdida pelo elemento escravo. Assim, o Candomblé baiano poderia ser interpretado como fonte de resistência cultural perante os valores da sociedade ocidental opressora. Em contrapartida, as Macumbas urbanas representariam o mínimo de solidariedade entre os homens, bem como a perda dos valores tradicionais africanos. Tratar-se-ia de uma dinâmica de degradação cultural: a passagem de formas religiosas puras para simplificações mágicas, curandeirismos afetados pela cultura ocidental e pela individualidade branca. A magia individualizante permitiria a exteriorização de instintos primários, os quais seriam responsáveis pelas atitudes criminosas que geraram as recorrentes batidas policiais nos terreiros de Macumba paulista.

Nesse viés, a oposição magia/religião, presente na obra de Durkheim (1993), passa a integrar o campo de estudos afro-brasileiros opondo-se Candomblés e 
Macumbas numa perspectiva dicotômica. No entanto, conforme expôs Dantas (1982), o próprio critério de pureza soa como construção ideológica que teve por objetivo controlar os cultos negros. Ao utilizar uma categoria nativa como analítica (pureza), o pensamento intelectual acabou por cristalizar o conteúdo de certas práticas, influenciando as relações de poder entre os terreiros na medida em que a categoria pureza tornou-se sinônimo de prestígio, assim influindo sobre os capitais simbólicos em disputa no campo religioso afro-brasileiro.

\section{A atual lógica da reafricanização e a relação entre campo afro-religioso e sociedade envolvente}

Na visão de autores como Prandi (1991), Silva (1995), Lépine (2005) e Frigério (2005), as tentativas de retorno à África constituem a tendência atual nas religiosidades de matriz africana. Nesse processo, africanização / reafricanização compreende uma série de reformulações que inclui a substituição da oralidade pela adoção de escritos produzidos pelos próprios adeptos, ou ainda importados da produção antropológica, com base nas etnografias de Roger Bastide e Pierre Verger. Demonstra-se uma incessante busca pela pureza de culto perdida nos processos de aculturação pósdiáspora. Ainda configuram características do movimento as viagens ao continente africano, cujos objetivos se relacionam com a compreensão dos cultos em seu caráter seminal, bem como o abandono das imagens de santos católicos e de outras influências que não configurem a idéia de matriz africana, verificando-se processos ativos e permanentes de desincretização ritual e cosmológica.

Decerto, o desenvolvimento das religiões de matriz africana no país esteve acompanhado de uma série de conflitos e situações de repressão concreta sobre seus adeptos. Deve ser destacado que o nexo subjacente a essas atitudes repressivas baseia-se num dualismo entre uma lógica racional, hegemônica e colonizadora, em oposição aos aspectos mágico-religiosos advindos de uma cultura "subalterna", assim engendrandose relações de poder assimétricas. Desse modo, observam-se certas estratégias empreendidas por atores e instituições políticas do campo africanista, as quais desenvolvem artifícios de negociação com a sociedade envolvente visando atenuar aquelas relações de tensão. Em boa medida, essas estratégias encontram-se sob a tendência da reafricanização e apontam não apenas para um distanciamento das 
acepções mágicas, mas para um projeto de racionalização das práticas religiosas, tendo como ponto de referência central o continente africano e a cultura Iorubá.

Nesse ponto, seria correto admitir que aquelas práticas mágicas, infestadas de entidades diabólicas e suas conotações eróticas e violentas, constituem pontos que sempre foram explorados nos ataques aos cultos afro-brasileiros. Na ótica de uma (re)construção teológica, tais acepções necessitaram ser repensadas, sobretudo a partir da recuperação de um Exu original, iorubano, livre do sincretismo que o demonizou. Ainda que não apenas a Quimbanda comporte a dimensão mágica que parece fornecer ainda mais combustível para os choques com outros segmentos sociais, pois Batuques, Candomblés e Xangôs são igualmente mágicos, é correto afirmar que a vertente quimbandeira contempla justamente os fatores que mais despertam os maiores tensionamentos com outros segmentos sociais e religiosos, especialmente com o pentecostalismo. Segundo os trabalhos de Oro (1997) e Prandi (2003), a perseguição contemporânea sobre o africanismo, deflagrada de forma contundente por parte da Igreja Universal do Reino de Deus, baseia-se exatamente na construção da fé deste segmento em oposição direta aos cultos afro-brasileiros, concebidos em analogia direta às ideias de demonização que fundamentam a experiência religiosa neopentecostal. Como ressaltou Prandi (2003, p.23), nesse processo, Exus e Pombagiras forneceram os signos demoníacos necessários ao projeto de ataque exercido pelos agentes do neopentecostalismo.

Um olhar pós-colonial sobre a quimbanda e as identidades afro-religiosas

* O sujeito descentrado e as tensões entre coletividade e indivíduo no campo africanista

As conexões iniciais entre a teoria pós-colonial e os estudos das religiões afro-brasileiras devem ser projetadas a partir de uma reflexão epistemológica. Considerando-se que as problemáticas que envolvem essas religiosidades sempre estiveram alimentadas por um antagonismo fomentado pela racionalidade ocidental, cuja expressão máxima se deu numa consideração negativa sobre seus sistemas de interpretação da realidade, a aderência a um marco teórico que reflita 
sobre esses sistemas de exclusão de saberes e visões de mundo trona-se fundamental. Basta retomar o histórico da repressão social sobre esses cultos que se torna clara a presença de um etnocentrismo desmascarado pela linearidade temporal subjacente à dicotomia atraso / progresso. Contudo, não basta ampliar uma já considerável base de análises sobre os discursos que construíram essa polaridade, devendo ser observados os possíveis contra-discursos que a combatem. Mais que isso, torna-se ainda relevante refletir sobre o potencial das alternativas políticas atualmente empreendidas para atenuar essas relações de poder assimétricas. Nesse caso, seria possível considerar alguma efetividade política na atual lógica da reafricanização? E caso existam efeitos políticos positivos, seriam essas estratégias isentas de novos condicionamentos ou novas relações de poder?

Parte-se do pressuposto que, ao conceber-se um projeto de (re)construção teológica, o qual visa atenuar as visões distorcidas sobre a religiosidade negra a partir da recuperação de fundamentos in África, ignora-se as dimensões vividas da cultura e engendram-se complexas relações de poder na busca por tal fundamento. Além disso, a constatação de uma disjunção entre agenciamentos políticos e prática religiosa adverte sobre a fraca ou precária identificação entre discursos e iniciativas de legitimação social e as experiências religiosas cotidianas, o que sugere a existência de possíveis condicionamentos identitários. É justamente em torno desses aspectos que as teorias do descentramento do sujeito (elaboradas no marco pós-colonial) demonstram-se contributivas.

De acordo com Hall (2005), esses processos de descentramento decorrem das transformações do mundo contemporâneo, as quais desvelaram uma produção de identidades cambiantes. Para o autor, as novas identidades, conectadas a um indivíduo fragmentado, se opõem às visões precedentes que detectavam a unidade de um sujeito racional e centrado. De outro modo, a questão da identidade passa por uma contínua e conflituosa produção. A ideia de continuidade, nesse caso, relaciona-se ao fato de que a negociação identitária encontra-se sempre permeada por relações de poder, em razão de que tais construções fundamentam-se em lógicas discursivas. Assim, a noção de identidade aqui elaborada configura-se como um ponto de sutura, um espaço de encontro de discursos e práticas que visam estabelecer posições a serem ocupadas pelos sujeitos a partir de sua interpelação por aqueles mesmos discursos. 
Segundo Wieviorka (2006), é possível identificar duas lógicas atuantes na expressão das diferenças que operam em constructos identitários: a lógica da reprodução, que visa assegurar a sobrevivência e a estabilidade do diferente; e a lógica da produção, que se processa a partir de construções inventivas. Enquanto as primeiras se encontram distantes das perspectivas identitárias básicas da modernidade (pois se baseiam em pertenças holistas típicas de um mundo regido pela tradição), as segundas promovem um processo de identificação renovado, num esquema de produção e reinvenção constante. Nessa lógica, Wieviorka (2006, p.147) ressalta que, quanto maior a amplitude do individualismo contemporâneo, maiores as possibilidades de amplificação das diferenças. Isso ocorre na medida em que o indivíduo participa de diferentes dimensões da vida coletiva a partir de distintas categorias de escolha, assim controlando sua própria existência. Por essa razão, os processos de definição das identidades coletivas são sempre complexos, verificando-se uma oscilação entre dois pólos básicos: o polo do fechamento, que demanda a submissão do indivíduo ao grupo; e o polo da abertura, através do qual as subjetividades são valorizadas. Essas possibilidades de configuração das pertenças exemplificam de maneira assertiva as complicações inerentes às identificações coletivas, cuja eficácia dependerá da abdicação das subjetividades em nome de projetos políticos comuns.

Aplicando essas noções ao tema aqui discutido, compreende-se que as relações entre abertura e fechamento, mencionadas por Wieviorka (2006), ou ainda as dinâmicas de maior ou menor individualização de acordo com a inserção dos sujeitos em determinadas coletividades permitem verificar as diferentes lógicas identitárias em jogo no campo africanista. Essas possibilidades configuram diferenciais decisivos no que se refere aos condicionamentos ligados aos agentes desse campo, seja nos agenciamentos políticos presentes na esfera pública, seja na experiência religiosa vivida nos templos.

Logicamente, as problemáticas que envolvem o africanismo em suas relações tensas com a sociedade envolvente demandam a construção de projetos políticos comuns, especialmente os de cunho reivindicativo. Contudo, no campo africanista esses empreendimentos se demonstram complexos, especialmente em razão da forte valorização das individualidades nesse mesmo campo. Como demonstram alguns autores (Cf. PRANDI, 1991; CORRÊA, 1998), já em sua origem o universo dos terreiros se organiza a partir de agências de culto autônomas e rivais entre si, num quadro em que as próprias características cosmológicas avalizam a valorização das 
subjetividades. Tal perspectiva é verificada na própria concepção de pessoa implicada nessas religiões, cujos sentidos partem de noções de filiação mística através das quais cada indivíduo adquire as qualidades mitológicas de suas respectivas divindades. Ocorre que orixás ou Exus não constituem entidades plenamente moralistas, fator que propicia uma total flexibilização nos códigos de conduta com os quais um agente pode se identificar. Dito de outro modo, trata-se de uma concepção de pessoa extremamente descentrada, e por essa razão, compatível com os predicados básicos das identidades contemporâneas. Como propõe Prandi (1991), tal perspectiva comporta inclusive uma dimensão compensatória na medida em que a vivência ritualizada de papéis sociais flexíveis (o transe místico é exemplo assertivo) permite ao iniciado experimentar aquelas condutas e ações que dificilmente seriam possíveis na vida cotidiana, alheia ao universo religioso, na qual muitas vezes os papeis vivenciados encontram-se condicionados pela estrutura social.

Por sua vez, as identidades forjadas na lógica da reafricanização reinserem os agentes sociais em estruturas de papeis pré-definidos, cujas posições se articulam de acordo com o domínio dos códigos religiosos racionalizados. Em outros termos, o processo de reafricanização gera novas formas de condicionamento identitário, as quais se conjugam a partir de novas relações de poder inferidas de acordo com as classificações associadas ao grau de pureza ritual e cosmológica.

De modo evidente, isso não invalida os escopos políticos desse movimento. É justamente em empreendimentos de conciliação das diferenças que se fundam as ações coletivas e identidades reivindicativas. Nesse caso, a reafricanização opera em dois sentidos principais. Por um lado, ao conciliar pertenças num formato padronizado, busca dirimir as contendas endógenas do campo afro-religioso, sobretudo aquelas que decorrem da individualidade fomentada no universo dos terreiros. Por outra via, o retorno simbólico ao continente africano também comporta dimensões estratégicas orientadas à ocupação de espaços na arena pública. Em termos identitários, é possível detectar aqui um posicionamento tático que ultrapassa a simples aproximação com os sistemas de representação religiosa mais aceitos socialmente (as religiosidades ocidentais), mas que busca enquadrar as religiões negras junto às demandas por políticas de restituição social, atualmente em voga no país.

Do ponto de vista pragmático, esses discursos reafricanizados vêm obtendo benefícios incontestáveis no campo das negociações políticas. Nesse sentido, a 
participação de agentes afro-religiosos em grupos de discussão de políticas públicas, a obtenção de recursos públicos para a afirmação cultural ou simplesmente a garantia de liberdade religiosa no país são tópicos plenamente detectáveis na atual esfera pública brasileira (Cf. LEISTNER, 2012). No entanto, também é fato que tais mobilizações não foram promovidas sem rearticular as relações de poder acima referidas, o que se expressa de modo claro nas contradições existentes entre os discursos políticos e as experiências religiosas. É nessa dimensão semiprivada, presente no cotidiano dos templos, que uma pertença descentrada é favorecida, algo tipificado de sobremaneira nas subjetividades que expressões rituais como a Quimbanda permitem.

Assim, observa-se que os discursos de reafricanização não apenas geram novos condicionamentos e relações de poder, mas ainda, e por esse mesmo motivo, esbarram numa frágil capacidade de mobilização. A compatibilidade entre os adeptos e essas propostas identitárias é facilmente rechaçada num contexto em que as subjetividades são valorizadas e continuamente atualizadas em performances rituais que possibilitam uma autoconstrução descentrada dos sujeitos. Assim, se é fato que os discursos de retorno à África vêm obtendo vantagens no campo político, é também correto constatar uma substancial distinção entre os grupos politicamente engajados e aqueles que desenvolvem suas práticas religiosas sem qualquer incursão pelas mobilizações da arena pública. Em síntese, enquanto as atividades dos grupos de mobilização reivindicativa encontram-se vazias, as sessões rituais de Quimbanda encontram-se lotadas.

\section{* A Quimbanda como espaço de subversão e linguagem de contestação}

Conforme proposto anteriormente, analisar os significados políticos da reafricanização nas religiões afro-brasileiras demanda um olhar para as tendências opostas a essa mobilização, sobretudo aquelas que se desenvolvem no cotidiano ritualístico dos terreiros. De modo reiterado, não se trata apenas de relativizar a ideia de que certas modalidades religiosas configurem um processo de degradação de expressões culturais específicas, mas de verificar os conteúdos políticos dessas próprias formas rituais alternativas em relação àquelas construções identitárias. A reflexão aqui proposta é a que questiona sobre a função política dessas experiências religiosas sincréticas, mágicas e pouco convencionais (outsiders), concebendo-as como espécie de texto. Trata-se de enunciados inscritos em determinadas performances rituais, cujos 
significados podem promover aquela atitude subversiva que revelou Bhabha (2001): devolver a inconsistência simbólica de discursos opressores e explicitar sua tenuidade.

Desenvolvida no âmbito dos estudos pós-coloniais, a noção de espaço híbrido enunciativo pode ser reapropriada como alternativa hermenêutica fecunda para analisar esses aspectos, seja no que se refere à relativização dos discursos de reafricanização, seja no que concerne à percepção sobre os aspectos contestatórios das práticas religiosas outsiders.

De acordo com Sérgio Costa (2006, p.92), a noção de um lugar de enunciação pós-colonial é elaborada a partir da tradição pós-estruturalista e da observação atenta sobe as relações entre discurso e poder. A questão central pressupõe a incursão dos agentes em espaços enunciativos livres das definições polares dentro/fora, objetivando posicionamentos no recinto médio das fronteiras que delimitam as identidades coletivas. A partir dessa perspectiva, a representação da diferença deve ser compreendida em seu caráter performático, mesmo aqueles processos de identificação baseados numa suposta legitimidade legada pela tradição e autenticidade. O princípio básico dessa concepção refere que o direito de significar a partir das regiões periféricas independe da recuperação de uma suposta tradição originária. Como assevera Costa (2006), esse direito encontra-se na propriedade inerente à tradição de ser constantemente reinventada através das contingências e contradições inscritas nas experiências sociais das minorias. Dessa maneira, de acordo com Bhabha (2001), o reconhecimento pressuposto pela tradição torna-se apenas uma forma parcial de identificação, na qual o passado não pode ser retomado sem a introdução de distintas temporalidades. A decorrência fundamental desse processo revela-se no estranhamento e na inconsistência presente em qualquer identificação concebida nos termos de uma tradição herdada.

Cabe ser recordada a advertência de Spivak (2010) de que são ilusórias as aspirações sobre um subalterno com possibilidade de fala. A problemática levantada pela autora revela-se na figura das prováveis subjetividades precárias que foram constituídas no colonialismo impregnado por uma violência epistêmica, a qual desqualifica os sistemas de representação do mundo desenvolvidos nos contextos subalternos. Dessa maneira, com uma fala desqualificada de antemão, de que serviria uma reivindicação baseada no tradicional e articulada por categorizações subalternas? A busca por fundamentos de origem, que acaba por retomar acepções dualistas, não reencontra nesse próprio dualismo uma ordem hierárquica na qual se encontra 
inferiorizada? É exatamente nesse sentido que a noção de terceiro espaço, de Homi Bhabha, revela algumas possibilidades analíticas. Para Bhabha (2001, p.65), um texto nunca é auto-suficiente, pois o lugar de enunciação é sempre atravessado pela différance da escrita. É justamente essa diferença que assegura a impossibilidade de transparência no processo de produção do sentido.

\begin{abstract}
A intervenção do Terceiro Espaço da enunciação, que torna a estrutura de significação e referência um processo ambivalente, destrói esse espelho da representação em que o conhecimento cultural é em geral revelado como um código integrado, aberto, em expansão. Tal intervenção vai desafiar de forma bem adequada nossa noção de identidade histórica da cultura como força homogeneizante, unificadora, autenticada pelo passado originário mantido vivo na tradição nacional do povo[...] É apenas quando compreendemos que todas as afirmações e sistemas culturais são construídos nesse espaço contraditório e ambivalente da enunciação que começamos a compreender porque as reivindicações hierárquicas da originalidade ou pureza inerentes às culturas são insustentáveis, mesmo antes de recorrermos a instâncias históricas empíricas que demonstram seu hibridismo (BHABHA, 2001, p.67).
\end{abstract}

Desse modo, se a estrutura de significação é ambivalente, os espaços existentes entre as polaridades discursivas permitem a captação de suas fragilidades. Em síntese, o conceito parte da idéia de que o discurso sempre dá passagem a um hiato, um intervalo próprio dos processos dialógicos, o qual não pertence a nenhum daqueles agentes que se encontram em diálogo. É nesse intervalo vazio e instantâneo, gerado entre a condição hegemônica e sua contingência que atuam as relações hierárquicas de poder. E será justamente esse o espaço pelo qual o subalterno pode apropriar-se das contradições expressas naquelas estruturas hierárquicas. Ao fazê-lo, o dominado devolve a precariedade daquilo que é tido como inconteste, tendo a possibilidade de construção de um discurso contra-hegemônico, contra-coerente, desestabilizador.

O que se conecta ao campo de estudos afro-religiosos diz respeito tanto às prováveis precariedades do discurso político centrado na reafricanização, quanto em relação à capacidade contestatória das expressões rituais opostas àqueles discursos. Como se observa na advertência de Spivak (2010), não é plausível que uma suposta originalidade, a tradição de uma religião pura como argumento de negociação, seja capaz de suplantar as lógicas coloniais que incidem opressivamente sobre as religiosidades afro-brasileiras. Não se trata de caracterizar como inválida, por exemplo, a descolonização de Exu, típica daquelas iniciativas. O que passa despercebido é que aquele Exu Quimbandeiro, marginalizado e demonizado simboliza a própria exclusão simbólica derivada das dicotomias ocidentalizadas do espiritismo, do catolicismo e do 
pentecostalismo, as desafiando ao introduzir a desordem, a sexualidade e a violência num universo em que tais categorias são supostamente estranhas. Ou seja, aquilo que deveria ser banido do universo religioso retorna como principal atrativo, como mercadoria simbólica valorizada por diferentes setores da sociedade. No caso do campo afro-religioso, o crescimento de expressões rituais como a Quimbanda é sintomático a esse respeito. Noutras palavras, o que antes seria rechaçado por uma totalidade religiosa universal passa a contribuir para sua fratura. Ao introduzir esses elementos de desordem no universo religioso, práticas como a Quimbanda e os cultos de Exus e Pombagiras determinam sua contaminação. Ao promoverem a matização da dicotomia bem e mal, subvertem o poder da totalidade do sagrado judaico cristão ocidental, que só pode sobreviver a partir da manutenção daquelas relações dicotômicas.

O que soa como algo instigante reside no poder contestatório e libertador que essas práticas sugerem no âmbito das experiências vividas, nas quais cada participante pode se auto-conceber a partir das dinâmicas de transgressão daquelas formas totalizantes. Poucos foram os estudiosos do assunto que assim compreenderam essas práticas. Esse é o caso de Lapassade e Luz (1972), que observaram a Macumba carioca e a Quimbanda como expressões de contracultura e libertação, numa espécie de psicanálise às avessas. Conforme demonstrou Carvalho (1990), mesmos cultos afrobrasileiros mais ortodoxos possuem a pretensão de ordem e estabilidade que os afasta das práticas mais sincréticas. Estas, ao contrário, ao incorporarem junto a seu tecido flexível diferentes códigos advindos dos processos de sincretismo acabaram por invertêlos e expressá-los numa direção oposta às perspectivas dominantes. Torna-se importante destacar que esta inversão de esquerda não recupera uma lógica dual. Trata-se antes de exacerbar o pólo negativo relegado pelos signos do discurso opressor e utilizá-los para desestabilizar suas próprias estruturas. Essa mesma relação se dá na figura da transgressão de limites proposta pelo erotismo que permeia essas formas religiosas, num exercício de inclinações e verdades do corpo e do espírito negadas pela visão de mundo ocidental e pelos costumes dominantes. Nessa perspectiva, por colocar-se no mundo ritualizado de espíritos de marginais, prostitutas e capetas urbanos, projeta-se além da censura e da culpa. 


\section{Algumas considerações para o debate}

Conforme referido acima, é fato que os projetos de legitimação empreendidos pelos atores do campo africanista vêm conseguindo certos avanços nas disputas travadas na esfera pública do país. Entretanto, também é factível perceber que tanto os redirecionamentos teológicos quanto os processos de reetnização simbólica encontram na vivência dos templos contrapontos fulminantes. É esse o sentido que um olhar sobre o que ocorre em práticas como a Quimbanda é capaz de salientar. Não se advoga em nome de uma passividade política. Apenas especula-se que os processos de construção de identidades cristalizadas, caso da reafricanização, não garantem eficácia ou poder de mobilização/articulação política. Também não se está sugerindo uma suposta eficácia política da desordem dionisíaca presente em cultos como os de Quimbanda. A questão consiste em observar na desordem introduzida por práticas como essas a contaminação de sistemas simbólicos tomados apriorísticamente como estáveis.

Retomando a paisagem etnográfica descrita no início do texto, numa sessão ritual de Quimbanda lá estavam eles: Exus e Pombagiras, os outsiders da cultura afrobrasileira. As performances rituais baseadas na carnavalização, na burla, no erotismo e na violência simbólica pareciam compor um recado: a desordem existe e penetra no universo das construções discursivas; assim, desestabiliza-se o centro, matizam-se as dicotomias e revelam-se as incoerências das narrativas que projetam manter as coisas em seus devidos lugares. 


\section{REFÊRENCIAS}

BALANDIER, Georges. Antropológicas. São Paulo: Editora Cultrix, 1976.

BARTHES, R. Mitologias. São Paulo: Difel, 2003.

BASTIDE, R. As religiões africanas no Brasil.1v. Paris: Press

Universitaires de France, 1960.

Estudos afro-brasileiros. São Paulo: Editora Perspectiva, 1983.

BECKER, H. S. Outsiders. Estudos de Sociologia do Desvio. Rio de Janeiro: Zahar Editores, 2008.

BHABHA, H. K. O local da cultura. Belo Horizonte: Editora da UFMG, 2001.

CAMARGO, C. P. F. de. Kardecismo e Umbanda. São Paulo: Livraria Pioneira Editora, 1961.

CARNEIRO, E. Candomblés da Bahia. São Paulo: Martins Fontes, 2008.

. Sabedoria popular. Rio de Janeiro: Marco Zero, 1957.

CARVALHO, J. J. R. O olhar etnográfico e a voz subalterna. Horizontes Antropológicos. Porto Alegre, ano 7, n 15, junho de 2001, pp. 107-147.

. Violência e caos na experiência religiosa. Religião e Sociedade.

Rio de Janeiro, ${ }^{\circ} 15$, Vol. 1, 1990, pp. 8-33.

CORRÊA, N. F. Sob o signo da ameaça: conflito, poder e feitiço nas religiões afro-brasileiras. São Paulo, Tese de Doutoramento em Antropologia, PUC/SP, 1998.

. Panorama das religiões afro-brasileiras do Rio Grande do Sul. IN: ORO, A. P. (Org.). As religiões afro-brasileiras do Rio Grande do Sul. Porto Alegre: Editora da universidade / UFRGS, 1994.

COSTA, S. Dois Atlânticos: teoria social, anti-racismo, cosmopolitismo. Belo Horizonte: Editora da UFMG, 2006.

DANTAS, B. G. Repensando a pureza nagô. Religião e Sociedade. Rio de Janeiro, n. 8, Julho de 1982, pp. 15-20.

DURKHEIM, É. Las formas elementales de la vida religiosa. Madrid: Alianza, 1993.

FRIGÉRIO, A. Reafricanização em diásporas religiosas secundárias: a construção de uma religião mundial. Religião e Sociedade. V. 25, n. 2, Rio de Janeiro, 2005, pp. 136-160.

HALL, S. A Identidade cultural na pós-modernidade. Rio de Janeiro: DP\&A, 2005. 
. “Quem precisa de identidade?". IN: SILVA, T. T. da. (org.), Identidade e Diferença. A perspectiva dos estudos culturais. Petrópolis: Vozes, 2000.

LALEYE, I. As Religiões da África Negra. IN: DELUMEAU, J. (org.). As grandes religiões do mundo. Lisboa: Editorial Presença, 2002.

LAPASSADE, G.; LUZ, M. A. O segredo da macumba. Rio de Janeiro: Paz e Terra, 1972.

LEISTNER, R. Os outsiders do além: um estudo sobre a Quimbanda e outras 'feitiçarias' afro-gaúchas. São Leopoldo, Tese de Doutoramento em Ciências Sociais, UNISINOS/RS, 2014.

Encruzilhada Multicultural: estratégias de legitimação das práticas religiosas afro-umbandistas no Rio Grande do Sul. In: Diversidade Cultural Afro-Brasileira: ensaios e reflexões. Brasília: Editora da Fundação Cultural Palmares, 2012, Pp. 249-266.

LÉPINE, C. Mudanças no candomblé de São Paulo. Religião e Sociedade. V. 25, n. 2, Rio de Janeiro, 2005, pp. 121-135.

LODY, R. Candomblé: religião e resistência cultural. São Paulo: Editora Ática, 1987.

ORO, A. P. O Atual Campo Afro-Religioso Gaúcho. Civitas, Porto Alegre, v. 12, n'.13, Set./Dez., 2012, pp. 556-565.

Neopentecostais e afro-brasileiros: quem vencerá esta guerra?

Debates do NER, Porto Alegre, ano 1, n.1, Nov., 1997, pp. 10-36.

ORTIZ, R. A morte branca do feiticeiro negro: umbanda.

Petrópolis: Vozes, 1978.

PRANDI, R. As religiões afro-brasileiras e seus seguidores. Civitas, Porto Alegre, v. 3, n. 1, Jun. 2003, pp. 15-33.

. Exu, de mensageiro a diabo: sincretismo católico e demonização

do orixá Exu. Revista USP, São Paulo, n. 50, 2001, pp. 46-65.

Os candomblés de São Paulo. São Paulo: Hucitec - Edusp, 1991.

RAMOS, A. As culturas negras no novo mundo. São Paulo: Nacional, 1979.

SHAW, Rosalind; STEWART, Charles. Introduction: probmeatizing sycretism. In: SHAW, Rosalind; STEWART, Charles. (Orgs.). Syncretism / Anti-Syncretism: the politics of religious synthesis. London: Routledge, 1994, pp. 1-26. 
SILVA, V. G. Exu do Brasil: tropos de uma identidade afro-brasileira nos trópicos. Revista de Antropologia da USP. São Paulo, volume 55, n. 2 , 2013, pp. 85-114.

Orixás da metrópole. Petrópolis/Rio de Janeiro: Vozes, 1995.

SPIVAK, G. Pode o subalterno falar? Belo Horizonte: Editora da UFMG, 2010.

WIEVIORKA, M. Em que mundo viveremos? São Paulo: Perspectiva, 2006.

RESENHA: BECK, Ulrich. A Europa Alemã: A crise do euro e as novas perspectivas de poder. Tradução de Kristina Michahelles. Rio de Janeiro: Paz \& Terra, 2015. $126 \mathrm{p}$. 